\title{
ANALYSIS OF SOME COMPONENTS OF BLOOD PROTEOME IN “HEALTHY POPULATION” OF RUSSIAN MEGAPOLIS
}

\author{
Andrew K. Martusevich ${ }^{1}$, Konstantin A. Karuzin ${ }^{2}$ \\ ${ }^{1}$ Privolzhsky Research Medical University, Nizhny Novgorod, Russia, \\ e-mail: cryst-mart@yandex.ru \\ 2 "Akapharm Itd.", Moscow, Russia
}

ABSTRACT - THE AIM OF THE STUDY was to study some components of blood proteome in healthy megapolis population.

METHODS: The study included 2025 people examined in the framework of preventive medical examination and referred to its results to 1-2 groups of health (the category of bealthy people) and did not have at the time of examination of chronic and acute diseases. The age of the examined persons was in the range of $20-50$ years (median -34.8 years). Total protein level, plasma concentrations of $\mathrm{C}$-reactive protein, ferritin and homocysteine were selected as markers of blood proteome.

Results: Our screening study allowed establishing that a significant part of the population of the megapolis, classified as practically healthy persons, has deviations from the physiological interval for a number of proteome components. This is most evident in shifts in plasma concentrations of C-reactive protein and ferritin. So, in more than half of the individuals levels of $\mathrm{C}$-reactive protein was outside the normal range. The distribution structure for ferritin shows the opposite trend.

KEYW ORDS — blood proteome, C-reactive protein, ferritin, homocysteine.

\section{INTRODUCTION}

Currently, proteomics, being one of the most widely known synthetic biological disciplines, is considered as a fundamental basis for the development of personalized laboratory diagnostics $[1,7]$. In whole, proteome is a set of all protein components of a biological sample [3]. It is shown that proteomic methods can study the protein structure of both biological fluids and various tissues of the body $[3,5]$. This allows us to distinguish biomarkers of a number of pathological conditions and diseases, carrying out their molecular diagnosis, including - at an early stage of their formation $[5,8,9]$. The most commonly analyzed biological sample for proteomic analysis is serum or plasma [6-10].

In most cases, proteomic analysis involves a mass spectrometric study of biological substrates $[7,12,15]$, but it is also possible to selectively evaluate individual components of the proteome by biochemical analysis
Article history:

Received 15 January 2019

Received in revised form 18 February 2019

Accepted 22 February 2019

of the concentration of metabolites $[2,3,8,11]$. This is especially important for cohort studies that are performed as part of screening testing of a large population $[2,5,9]$.

In recent decades, the emphasis of medicine has gradually shifted from diseases treating to preventive medicine $[12-14,17]$. This is due to the high frequency of prenosological conditions that require timely correction. In turn, such a statement of the problem is determined by the need for a detailed study of the prevalence of metabolic disorders, including shifts in proteome components in the population classified as healthy individuals $[5,11,12,17]$.

In this regard, the aim of the study was to study some components of blood proteome in healthy megapolis population.

\section{METHODS}

The study included 2025 people examined in the framework of preventive medical examination and referred to its results to $1-2$ groups of health (the category of healthy people) and did not have at the time of examination of chronic and acute diseases. The age of the examined persons was in the range of $20-50$ years (median -34.8 years).

All people included in the study, after obtaining informed consent, were subjected to extensive laboratory testing. Total protein level, plasma concentrations of C-reactive protein, ferritin and homocysteine were selected as markers of blood proteome. All these parameters were determined by standard laboratory methods. All patients were tested in the morning.

The gradation of the level of indicators was made according to the existing standard (reference) laboratory intervals. Additionally we used a quartile approach, highlighting the reduced and increased level of the parameter and four quartiles. The normal distribution of the trait values corresponding to the Gauss distribution was taken as the population norm. The structure of distribution of values of the parameter, essentially different from the last, was considered deviating.

The data were processed in the software package Statistica 6.1. 


\section{RESULTS}

The quartile analysis of the formed group of people allowed to establish that the structure of the distribution of the values of the selected proteome components differs significantly from the standard Gauss distribution (Fig. 1-4). Thus, the level of total protein is found at low values in $14.93 \%$ of the examined individuals (Fig. 1). In addition, attention is drawn to the fact that this parameter is recorded at the lower limit of the norm corresponding to 1 quartile in $33.79 \%$ of people.

Interesting data were obtained with respect to the level of C-reactive protein in blood plasma (Fig. 2). It was revealed that among the examined people, referred to the results of preventive examination to the category of practically healthy persons, in $54.81 \%$ of cases there was an increased level of the indicator. In addition, in $14.97 \%$ of the examined people the concentration of C-reactive protein was fixed at the upper limit of the norm corresponding to the $4^{\text {th }}$ quartile.

The most significant deviation from the standard distribution structure was revealed for the main iron transport blood protein-ferritin (Fig. 3). It was found that the reduced level of this indicator was typical for $26.87 \%$ of the surveyed group of people, and in $47.65 \%$ of cases it was at the lower limit of the norm (1 quartile).

According to the homocysteine concentration, the formed group corresponded to the Gauss distribution to the greatest extent, however, a certain shift was observed for this parameter as well (Fig. 4). Thus, $11.68 \%$ of the surveyed persons had a reduced value of the indicator, and it was at the lower limit of the norm in $31.31 \%$ of cases. On the contrary, an increased level of homocysteine was recorded in $5.79 \%$ of people.

\section{DISCUSSION}

Laboratory biomarkers are known to be the basis of personalized medicine $[1,3,5,8,12,14]$. These include components of the proteome such as C-reactive protein, ferritin and homocysteine.

C-reactive protein, which belongs to the category of acute phase proteins, is one of the markers of inflammatory reaction $[4,5]$. In addition, its level is considered as a predictor of various chronic diseases, including cardiovascular disease and degenerative diseases of the musculoskeletal system $[16,17]$. In our study it was found that more than $54 \%$ of the population of the megapolis, belonging to the category of bealthy persons, has an increased level of the indicator. This indicates the need for their in-depth study for diagnosis and early correction of prenosological conditions.

Also, the study showed that a significant part of the population of a large city (about 27\%) has devia-

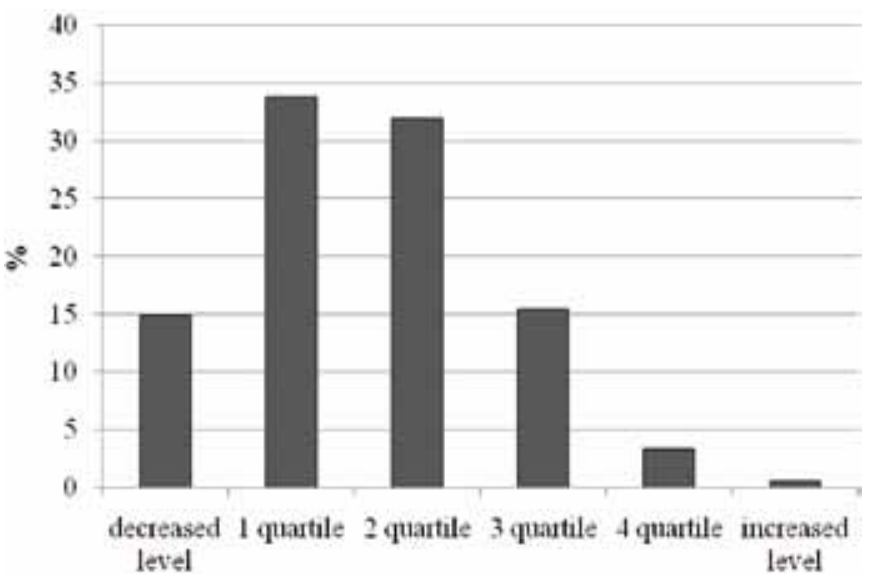

Fig. 1. Quartile structure of total level of blood protein in healthy people

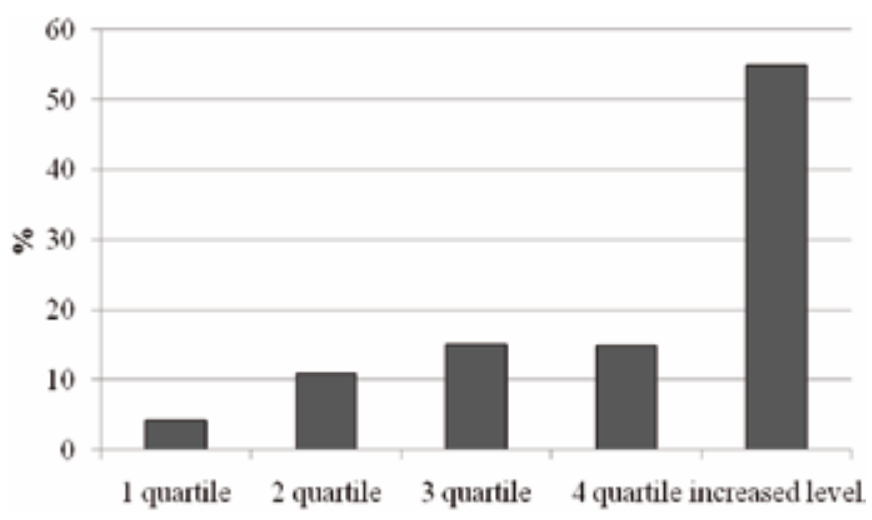

Fig. 2. Quartile structure of C-reactive protein level in the blood of healthy people

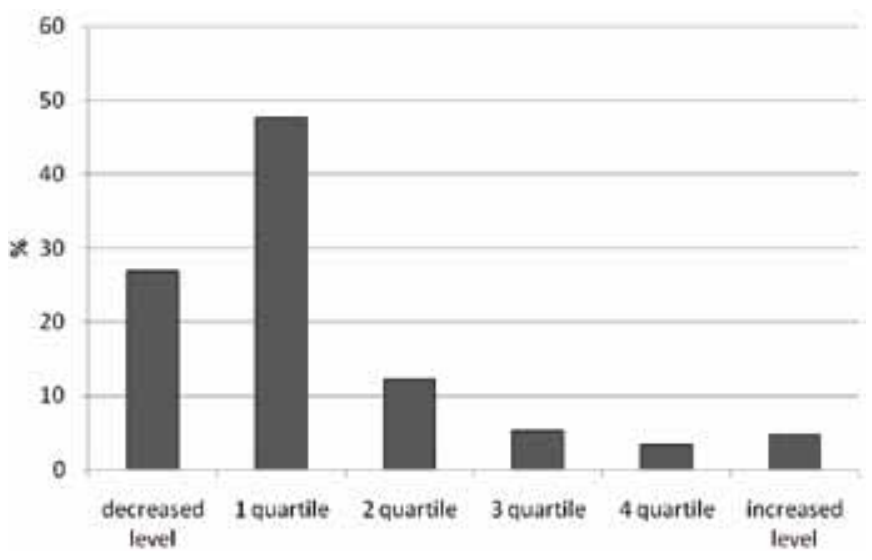

Fig. 3. Quartile structure of ferritin level in the blood of healthy people 


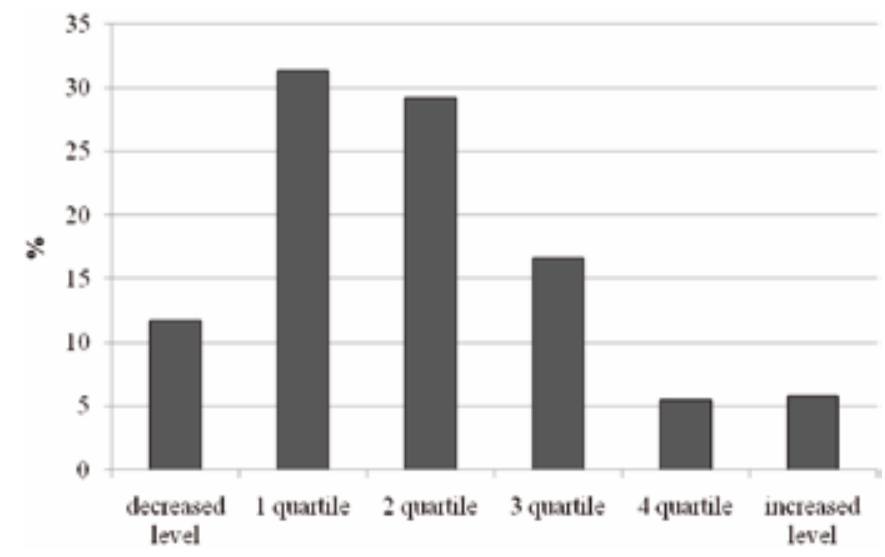

Fig. 4. Quartile structure of homocysteine level in the blood of healthy people

tions of ferritin concentration from the physiological level, and about half of the people demonstrate the trend to reduce the level of this metabolite. Such data confirm the literature data on the heterogeneity of the population according to this criterion [11], and there is evidence that both the increase and decrease in the level of this parameter is associated with an increase in the risk of cardiovascular disease $[8,11]$.

Similar shifts are shown by us for the concentration of homocysteine in the blood plasma of residents of the megapolis. In total, about $43 \%$ of the surveyed people had a reduced value of the parameter or located at the lower limit of the norm. It is also considered as a negative criterion, which is a potential marker of prenosological disorders, including neurological disorders (in particular, Alzheimer's disease [10], sleep disorders [2]) and even sexual dysfunction [13].

Thus, an extensive study has demonstrated the presence of significant shifts in the plasma concentration of a number of proteome components, which requires further in-depth analysis for personalized correction.

\section{CONCLUSION}

Our screening study allowed to establish that a significant part of the population of the megapolis, classified as practically healthy persons, has deviations from the physiological interval for a number of proteome components. This is most evident in shifts in plasma concentrations of C-reactive protein and ferritin. So, more than half of the individuals having levels of $\mathrm{C}$-reactive protein outside the normal range. The distribution structure for ferritin shows the opposite trend.

\section{REFERENCES}

1. Barrachina M.N., Calderón-Cruz B., FernANDEZ-Rocca L., García Á. Application of Extra- cellular Vesicles Proteomics to Cardiovascular Disease: Guidelines, Data Analysis, and Future Perspectives // Proteomics. - 2019. - Vol. 19, N 1-2. - el800247.

2. Chen T.Y., Winkelman J.W., Mao W.C. et al. Short Sleep Duration Is Associated With Increased Serum Homocysteine: Insights From a National Survey // Clin. Sleep Med. - 2019. - Vol. 15, N 1. P. 139-148.

3. Emilsson V., Ilkov M., LAmb J.R. ET AL. Co-regulatory networks of human serum proteins link genetics to disease // Science. - 2018. - Vol. 361, N 6404. P. 769-773.

4. Figarska S.M., GustafsSon S., Sundström J., Ärnlöv J., Mälarstig A., Elmståhl S., Fall T., LIND L., INGELSSON E. Associations of Circulating Protein Levels With Lipid Fractions in the General Population // Arterioscler. Thromb. Vasc. Biol. 2018. - Vol. 38, N 10. - P. 2505-2518.

5. Ho J.E., Lyass A., Courchesne P. et AL. Protein Biomarkers of Cardiovascular Disease and Mortality in the Community // J Am Heart Assoc. - 2018. Vol. 7, N 14. - pii: e008108.

6. Hu C.P., Shao J.M., Yan J.T. ET AL. Study on the distribution of serum homocysteine and on multistepwise regression analysis of the associated factors in the population of community areas in Wuhan // Zhonghua Liu Xing Bing Xue Za Zhi. - 2004. - Vol. 25, N11. - P. 945-948.

7. Jensen S.B., Hindberg K., SOlomon T. et AL. Discovery of novel plasma biomarkers for future incident venous thromboembolism by untargeted synchronous precursor selection mass spectrometry proteomics // J. Thromb. Haemost. - 2018. - Vol. 16, N9. - P. 1763-1774.

8. KiIP I.T., Voors A.A., SWInkels D.W. eT AL. Serum ferritin and risk for new-onset heart failure and cardiovascular events in the community // Eur. J. Heart Fail. - 2017. - Vol. 19, N 3. - P. 348-356.

9. Liang X., Du Y., Wen Y. et Al. Assessing the Genetic Correlations Between Blood Plasma Proteins and Osteoporosis: A Polygenic Risk Score Analysis / Calcif. Tissue Int. - 2019. - Vol. 104, N 2. - P. 171-181.

10. Ma F., Wu T., Zhao J. et al. Plasma Homocysteine and Serum Folate and Vitamin B12 Levels in Mild Cognitive Impairment and Alzheimer's Disease: A Case-Control Study / / Nutrients. - 2017. - Vol. 9, N 7. - pii: E725.

11. Silvestre O.M., Gonçalves A., Nadruz W.Jr. ET AL. Ferritin levels and risk of heart failure-the Atherosclerosis Risk in Communities Study // Eur. J. Heart Fail. - 2017. - Vol. 19, N 3. - P. 340-347.

12. Tanaka T., Biancotto A., Moaddel R. et Al. Plasma proteomic signature of age in healthy humans // Aging Cell. - 2018. - Vol. 17, N 5. - e12799.

13. Yang H.F., Kao T.W., Lin Y.Y. et al. Does Serum Homocysteine Explain the Connection Between Sexual Frequency and Cardiovascular Risk? // J Sex Med. - 2017. - Vol. 14, N 7. - P. 910-917. 
14. Zhan Y., Tang Z., YU J. Serum ferritin, diabetes, diabetes control, and insulin resistance // Acta Diabetol. - 2014. - Vol. 51, N 6. - P. 991-998.

15. Zhang Y., Wang C.C., NiU R. Screening on serum biomarkers in idiopathic pulmonary fibrosis patients by proteomics technology // Zhonghua Liu Xing Bing Xue Za Zhi. - 2018. - Vol. 39, N 8. - P. 1117-1120.

16. Su J., Cur L., Yang W. ET EL. Baseline high-sensitivity C-reactive protein predicts the risk of incident ankylosing spondylitis: Results of a community-based prospective study // PLoS One. - 2019. - Vol. 14, N 2. - e0211946.

17. Hsu P.F., PAN W.H., YIP B.S. C-Reactive Protein Predicts Incidence of Dementia in an Elderly Asian Community Cohort // J Am Med Dir Assoc. - 2017. - Vol. 18, N 3. - P. 277.e7-277.e11. 